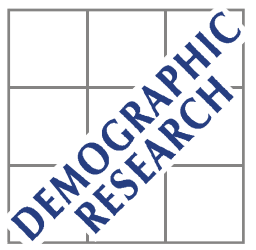

Demographic Research a free, expedited, online journal of peer-reviewed research and commentary in the population sciences published by the Max Planck Institute for Demographic Research Konrad-Zuse Str. 1, D-18057 Rostock · GERMANY www.demographic-research.org

DEMOGRAPHIC RESEARCH

SPECIAL COLLECTION 2, ARTICLE 12

PUBLISHED 16 APRIL 2004, PAGES 305-330

www.demographic-research.org/special/2/12/

DOI: $10.4054 /$ DemRes.2004.S2.12

Research Article

\title{
Increasing excess mortality among non- married elderly people in developed countries
}

Tapani Valkonen

Pekka Martikainen

Jenni Blomgren

The papers in this special collection were presented at the seminar "Determinants of Diverging Trends in Mortality", held at MPIDR, Rostock on 19-21 of June, 2002. The seminar was organized by the Max Planck Institute for Demographic Research and the Committee on Emerging Health Threats of the International Union for the Scientific Study of Population.

(C) 2004 Max-Planck-Gesellschaft. 


\section{Table of Contents}

1 Introduction 306

$2 \quad$ Data 307

3 Results 308

3.1 Average trends in marital status differences in 308

3.2 Country-specific changes in mortality by marital 309

4 Discussion $\quad 310$

4.1 Weaknesses in the data 310

4.2 Changes in the relative and absolute excess 312

4.3 Possible causes of the increase in the excess 313 mortality of non-married elderly people

$5 \quad$ Acknowledgements $\quad 314$

$\begin{array}{ll}\text { References } & 315\end{array}$

Appendix (Sources of data, Tables, Figures) 317 


\title{
Increasing excess mortality among non-married elderly people in developed countries
}

\author{
Tapani Valkonen ${ }^{1}$ \\ Pekka Martikainen ${ }^{2}$ \\ Jenni Blomgren ${ }^{3}$
}

\begin{abstract}
This article analyses changes in marital status differences in mortality from approximately 1970 to 1995 among men and women aged 65-74 in ten developed countries (Belgium, Canada, Denmark, England and Wales, Finland, France, Japan, Netherlands, Norway and Sweden). Data were obtained from the United Nations Demographic Yearbooks and national statistical sources. According to the results there has been a trend towards increasing excess mortality among single men compared to married men and single, divorced and widowed women compared to married women in most western European countries and Canada in the 1980s and 1990s. This has been brought about by a more rapid decline in mortality among married persons and a slower decline or even an increase among non-married persons. In Japan the excess mortality of non-married men and women decreased.
\end{abstract}

1 Department of Sociology, University of Helsinki, P.O.Box 18, 00014 University of Helsinki,

Finland. E-mail: Tapani.Valkonen@helsinki.fi

2 University of Helsinki. Email: Pekka.Martikainen@helsinki.fi

3 University of Helsinki. Email: Jenni.Blomgren@helsinki.fi 
Demographic Research - Special Collection 2: Article 12

-- Determinants of Diverging Trends in Mortality --

\section{Introduction}

A huge number of studies have shown that single, divorced and widowed persons have higher mortality than married persons. This excess mortality is usually considered to be partly due to the selection of higher-risk persons to the non-married states and partly to the protective effects of marriage (Hu and Goldman 1990, Joung 1996). The relative contributions of selection and causation are likely to vary according to time and place.

Although there is no shortage of studies on marital status mortality differences, few studies have dealt with trends in these differences. One exception is the study by Hu and Goldman (1990), which deals with marital status differences among men and women aged 25-64 in 16 developed countries. The years covered by the data vary from country to country starting from the 1950s or 1960s and ending in the 1970s or early 1980s. According to the results the relative excess mortality of single, divorced and widowed persons had increased in most countries because of a more rapid decline among married than non-married persons. The authors suggested that the observed increase in the excess mortality of non-married groups from the 1950s to the early 1980s could be due to increasing protective effects of marriage during a time of rapid technological development, an increasing degree of selection in terms of type of person who remains unmarried or whose marriage is terminated, or the inappropriateness of the relative mortality ratio as a measure of excess mortality (Hu and Goldman 1990).

Hajdu, McKee and Bojan (1995) studied changes in premature (under 65) mortality by marital status in Hungary and in England \& Wales, and Watson (1995) in Poland and in East-Germany in the 1980s. National studies on trends in mortality by marital status have been published for the Netherlands (Joung 1996) and for Finland (Martelin 1996, Koskinen, Martelin and Rissanen 1999). All these studies suggest that the development of mortality has been more favourable in the married group than in the non-married groups.

Valkonen (2001) studied trends in mortality by marital status in age groups 45 to 54 and 65 to 74 in thirteen European countries from 1970 to the latest year for which data were available. According to the results there was a substantial increase in the excess mortality of non-married compared to married women aged 65 to 74 in all western and northern European countries that were studied. A similar increase was observed among men aged 65 to 74 in four Nordic countries and the Netherlands. In age group 45 to 54 the general tendency was also towards increasing differences in mortality but there was more variation between countries than in age group 65 to 74 years.

This paper is an extension of the study by Valkonen (2001). It includes a more detailed analysis of the trends in mortality in age group 65 to 74 , in which an unexpected increase in the excess mortality of the non-married groups was found. A 
more thorough analysis is needed in order to develop policies to counter the unfavourable development. Persons without the support of a marital partner seem to be an increasingly vulnerable sub-population, the size of which is increasing along with the aging of the population. This paper analyses trends in mortality by marital status among persons aged 65 to 74 years in ten developed countries including two nonEuropean countries, from 1970 to mid-1990s.

There is a well known methodological problem in studies on trends in mortality differences: there are several ways of measuring the size of differences (inequality), and the conclusions about changes often depend on the measure chosen (see e.g. Mackenbach and Kunst 1997, Valkonen 1999). For example, when death rates decrease, the relative differences may increase, whereas the absolute differences may decrease. Relative differences of mortality (mortality ratios) are used more commonly in demographic and epidemiological studies than absolute differences. Absolute differences and changes in them are, however, equally or even more important because they more directly reflect the public health significance of excess mortality of high-risk groups. In this paper we will study trends in both absolute and relative mortality differences.

\section{Data}

The study covers eight western European countries (Belgium, Denmark, England and Wales, Finland, France, Netherlands, Norway, Sweden), Canada, and Japan. For these countries comparable data were available at least until 1994. The main source of data for populations, deaths and death rates by sex and marital status in age group 65 to 74 were United Nations Demographic Yearbooks for the years 1974-1996. In addition, published and unpublished data from national statistical offices were used (see the list of sources in Appendix). The UN Demographic Yearbook uses 10-year age groups. Therefore, we were not able to use a more detailed age-classification within the age band 65-74. If data were available only for the number of deaths and death rates, the distribution of population by marital status was estimated on the basis of this information.

An attempt was made to obtain data for the years 1970, 1980, 1990 and for the latest year for which data were available. Linear interpolation or extrapolation was used to adjust the data to make the death rates and population distributions by marital status cover the years 1970, 1980, 1990 and 1996 (Belgium, Denmark, France, Japan, the Netherlands) or the years 1971, 1981, 1991 and 1997 (Canada, England and Wales, Finland, Norway, Sweden). In the analysis adjacent years (for example 1970 and 1971) are treated as belonging to the same time period (presented as 1970/71). Data on causes 
of death were not available in the sources used for this study and the analysis is, therefore, restricted to all-cause mortality only.

\section{Results}

\subsection{Average trends in marital status differences in mortality in ten countries}

Table 1 shows the (unweighted) average shares of the four marital status groups in the countries studied from 1970/71 to 1996/97. Due to the decline of mortality the share of both widowers and widows diminished markedly during the whole period covered. On the other hand, the proportion of divorced men tripled and that of divorced women almost tripled. There was a slight decrease in the percentage of single men, but a much clearer decrease in the percentage of single women. As the net result of these trends the percentage of married men remained almost constant during the period covered $(77 \%$ to $78 \%$ ), but the percentage of married women increased from $46 \%$ to $55 \%$.

The changes in the marital status distribution in the individual countries usually followed the average pattern described above: the share of widowed persons diminished and that of divorced persons increased in all countries. The percentage of single persons diminished in almost all countries and periods. The main exception is Japan, where being single was very exceptional in 1980 ( $0.9 \%$ among men and $1.2 \%$ among women) but has become more common by 1996 (1.7\% among men and 3.9\% among women).

Figure 1 shows the average death rates by marital status for the countries covered by the study from 1970/71 to 1996/97. Logarithmic scale is used and the figure thus shows changes in relative mortality differences between the groups. In 1970/71 the death rates for single, divorced and widowed men were very close to each other. The death rates decreased in all marital status groups from 1970/71 to 1996/97, but relatively more rapidly in the married than non-married groups. The mortality of widowed men diminished more rapidly than that of single and divorced men. The excess mortality of non-married men compared to married men varied from $38 \%$ (single and divorced) to $41 \%$ (widowed) in 1970/71. The relative excess mortality of these groups compared to married men increased systematically from period to period (Figure 2). In 1970/71 the excess mortality of all non-married men compared to married men was $40 \%$, but by $1996 / 97$ the excess had increased to $68 \%$.

Among women the overall picture is the same as among men, although the relative excess mortality of the non-married groups was somewhat smaller than among men (Figures 1 and 2). Like among men the mortality of non-married women decreased relatively less rapidly than that of married women. Among widows mortality decreased more rapidly than among single and divorced women. The average relative excess 
mortality of all non-married women was $26 \%$ in $1970 / 71$, and it increased to $48 \%$ in 1996/97.

A linear scale is used in Figure 3 to present the same data that were presented in Figure 1 using a logarithmic scale. Figure 4 shows the trends in the absolute differences in death rates between the non-married groups and the married group. The figures show that the increase in the absolute excess mortality of the non-married group is not as clear as the increase in the relative excess mortality shown above. Because the overall level of mortality has decreased, the absolute excess mortality of the non-married category has increased only slightly despite the large increase in the relative excess mortality. In total the absolute excess mortality of all non-married men compared to married men increased from 17.0 to 18.2 deaths/1000 (by 7\%). The absolute excess mortality among non-married women increased from 5.8 to 6.3 deaths/1000 (9\%). As Figure 4 shows, there was no increase in the 1970s. All of the increase in the absolute excess mortality occurred from 1980/81 to 1996/97 both among men and women. We will, therefore concentrate mainly on this period in the rest of the paper.

\subsection{Country-specific changes in mortality by marital status}

Figures 5 and 6 show the trends in mortality by marital status for each of the ten countries. Table 2 gives changes in the absolute excess mortality of each of the three non-married marital states as compared to the married state. Among men the absolute excess mortality of single men increased in all countries from 1980/81 to 1996/97 except in Japan and Belgium. As Figure 5 shows the mortality of single men even increased in Norway, Canada, Denmark and the Netherlands. In Japan the mortality of single men decreased rapidly. However, Japan is exceptional because of the extremely low percentage of single men.

The mortality of divorced men decreased in all countries except Japan. The trends in the absolute excess mortality of divorced men are not as uniform as those among single men. The excess increased in four but decreased in six countries.

With the exception of Denmark, the changes in the mortality of widowers were relatively similar to those among married men, and the absolute excess mortality slightly diminished in most countries. However, due to the rapidly declining share of widowers and the large increase in the excess mortality of single men, the excess mortality of all non-married men taken as one group increased in all countries except Belgium, Japan, and France.

As for men, the excess mortality of single and all non-married women increased in most countries. Japan and Norway were the only exceptions. The patterns of change 
among divorced and widowed women differed from those among men, as the excess mortality increased in almost all countries, whereas this was not the case among men.

On the basis of the absolute mortality changes presented above the ten countries can be classified into four groups:

1. Canada, Denmark and Netherlands. In these countries the absolute difference in mortality between non-married and married increased strongly both among men and women.

2. England and Wales, Finland and Sweden. In these countries the absolute excess mortality of non-married compared to married men and women also increased but not as much as in group 1.

3. Belgium, France and Norway. In these countries the direction of changes in the excess mortality was different among men and women.

4. Japan. The absolute excess mortality of non-married men and women decreased.

Table 3 shows changes in the relative excess mortality of the non-married groups. For example, the death rate for single men in France in 1980/81 was 41.3\% higher than that of married men. In 1996/97 this relative excess was 58.9\%. The change in the relative excess mortality in percentage points was $17.6(58.9 \%-41.3 \%)$.

The relative excess mortality of the group of all non-married persons increased in all countries among both men and women. When the non-married marital states are looked at separately, eight cases of decrease in the relative excess are observed (Table 3 ). Four of these cases are for Japan, some are relatively small decreases and at least some of them may be due to errors or stochastic variation in data. It seems that an increase in the relative excess mortality of the non-married groups has been almost universal in the group of countries studied here and probably also in other countries in which death rates have decreased and marriage has previously not been nearly universal.

\section{Discussion}

\subsection{Weaknesses in the data}

Due to the limitations of the statistical sources we had to use death rates calculated for the entire 10-year age band without more detailed age-classification. To estimate to what extent this may have caused bias, we calculated age-standardized death rates for 1980/81 and 1996/97 for three countries (Finland, France, and Sweden) for which data by 5 -year age groups were available. Results for both years and all three countries showed that age-standardization had only a small effect on the differences in mortality between married, single and divorced persons, as the age-distributions of these groups 
in the age-band 65 to 74 are relatively similar. On the other hand, age-standardization had a relatively strong effect on the mortality of widowed persons, as the share of older persons (70 to 74 years) was larger among widowed people than other marital states. The unbiased (age-standardized) death rates for widowed persons are therefore smaller than those presented in Figures 5 and 6. The excess mortality of widowed compared to married persons varied by year and country. On average the excess was 22 per cent smaller when 5-year age-standardized death rates were used instead of the unstandardized 10-year death rates. Furthermore, results from a previous study on Finnish widowers indicate that even 5-year age-standardization can be inaccurate and cause bias in the mortality rates (Martikainen and Valkonen 1995). This should be taken into account, for example, when looking at Figures 5 and 6, in which the death rates for widowed persons should be clearly lower.

Since this study focuses on changes in the differences rather than the differences in themselves, the bias caused by the lack of age-standardization is relevant only to the extent it has an effect on the results concerning changes in excess mortality. Table 4 shows a comparison of the results on changes in the absolute excess mortality of the non-married marital states when measured without age-standardization (as in Table 2) and with age-standardization for the three countries. The comparison shows that the age-standardized figures are, in many cases, different from the unstandardized figures. However, with one small exception, the signs of the changes are the same. The use of age-standardized figures thus does not change the main broad conclusions for this relatively homogenous group of three countries although the exact degree of change may be affected. However, due to the possibility of bias in our data detailed comparisons of countries are not advisable. Future analyses of marital status differences should use more detailed age-classifications and adjust for the differences in agestructure within broad age groups.

In addition to the crude age-classification, there may be other weaknesses in the data. There are some irregularities in the trends presented in Figures 5 and 6, which may be due to stochastic variation or errors in data, caused for example by typing-errors in publications or inconsistencies in the information on marital status in the death and population records. The use of interpolated and extrapolated death rates may also have some effects on the trends.

Cohabitation without formal marriage has become relatively common in many developed countries during the period studied here and the share of single, divorced and widowed persons who actually live with a partner has increased. However, this bias is likely to be conservative, because the increase of the proportion of cohabiting persons in the non-married groups should lead to a decrease in their excess mortality rather than to an increase as observed here. 
Moreover, the percentage of cohabiting persons in the elderly non-married age group studied here was still relatively small in the 1990s. For example, in Finland, where cohabitation is common compared to most other countries, only thirteen percent

of all non-married men and four percent of all non-married women aged 65 to 74 were cohabiting in 1990 (Statistics Finland 1991 and 1992).

\subsection{Changes in the relative and absolute excess mortality}

According to the results, the relative excess mortality of single, divorced and widowed persons increased from 1980/81 to 1996/97 with very few exceptions among men and women aged 65-74 in all countries studied. A similar tendency towards increasing relative excess mortality was observed by $\mathrm{Hu}$ and Goldman (1990) in their study on mortality trends among 25-64 year olds from the 1950s to the early 1980s in 16 countries.

The increase in the relative excess mortality was connected with the overall decline in mortality. Trends in other mortality differentials than marital status differences also show a similar tendency towards increasing relative differences when mortality decreases (Valkonen 1999). A related phenomenon is that relative mortality differences by sex, socioeconomic status, and other variables tend to decrease by age, whereas absolute differences increase. The increase in the relative excess mortality, which was found to have occurred in all countries studied, may be considered at least partially a measurement artefact. The results on relative mortality differences do not necessarily imply that the mortality situation of non-married as compared to married persons would have worsened.

Our results show, however, that even the absolute excess mortality of non-married persons increased in most countries from 1980/81 to 1996/97. This increase took place in all non-married groups among women and among single men. The absolute excess mortality of divorced and widowed men also increased in several countries. The most clear exception was Japan where the absolute excess mortality of the non-married group decreased both among men and women. The increase in the excess was mostly due to the less rapid absolute decrease in mortality in the non-married groups than in the married group, but among women in some countries (Denmark, the Netherlands and Canada), the increase was due to a halt of the decrease or even an increase in mortality in some non-married states.

In summary, there has been a trend towards increasing mortality disadvantage of single elderly men and all groups of non-married elderly women in most western European countries and Canada in the 1980s and 1990s. 
Demographic Research - Special Collection 2: Article 12

-- Determinants of Diverging Trends in Mortality --

\subsection{Possible causes of the increase in the excess mortality of non-married elderly people}

Part of the excess mortality in the non-married states is due to the selection of persons with higher than average risk to these states. As suggested by Hu and Goldman (1990) the increase in the excess mortality could, consequently, be due to a strengthening of this selection mechanism. This could take place, particularly, if the relative size of the less-privileged group decreases and the group becomes more deviant from the average population. The share of single persons in age group 65 to 74 decreased in most countries during the study period. Consequently, it is possible that the increase in the absolute excess mortality of single persons was, at least to some extent, due to an increased selectivity. On the other hand, the rapid decline in the excess mortality of single persons in Japan is likely to be associated with the increased percentage of single persons.

However, the share of divorced persons has increased in all countries. Divorced persons should, therefore, be less negatively selected than before and their absolute excess mortality should have diminished but, in reality, it increased among women and remained relatively stable among men. Therefore, increased selection is unlikely to explain the increase in excess mortality among divorced persons.

Also the percentage of widowed men and women diminished in all countries. At the same time the absolute excess mortality of widowed women increased in almost all countries. However, it may be difficult to link this increase to an increased selectivity in becoming a widow, because the decrease in the share of widows was due to increasing life expectancy. Moreover, if increased selectivity would be relevant, we would expect an increase in absolute excess mortality among widowed men as well.

The increase in the excess mortality of non-married men was mainly due to the increase of the excess among single men only, and this may be explained, at least partly, by increased selection. The increase in the excess mortality of non-married women cannot, however, be accounted for by selection as the increase was observed in all non-married groups. Therefore it seems that at least among women there have been changes in the causal mechanisms affecting marital status differences in mortality: the protective effect of marriage and /or the adverse effects of the non-married states may have increased.

A slow-down in the decline in mortality and in some cases even an increase was observed in all non-married groups among women in most countries since 1980. This seems to imply that an increase in the vulnerability of women without a partner has been an important mechanism underlying the results. 
One hypothesis for the explanation of the (assumed) increased vulnerability of elderly non-married women is that urbanization, increased social and geographic mobility, the decrease in the number of children per women and other societal trends have reduced the possibilities (and willingness) of descendants, other relatives, and neighbours to help and care for elderly women without a partner (Valkonen 2001). This hypothesis is in accordance with changes in the living arrangements of elderly people: the share of persons living alone among non-married elderly persons has increased since the 1970s in all European countries for which data are available (Pampel 1992, Palloni 2002). In Finland, for example, the percentage of non-married women aged 6574 living alone increased from $64 \%$ to $74 \%$ from 1980 to 1995 . Among men the increase was from 55\% to 63\% (estimated on the basis of Finnish Censuses of 1980 and 1995). The increase in the proportion of non-married persons living alone is, however, not large enough to explain a major part of the increase in the excess mortality of nonmarried persons even if we assume that living alone has a strong negative effect on health. Nevertheless, direct measures of changes in help and care among non-married elderly are needed to fully test this proposition.

Another hypothesis is that the mortality of married people has declined more rapidly, because they have adopted healthy dietary and drinking habits and stopped smoking more frequently than non-married persons. Such changes may be brought about by the increasing protective effects of marriage in terms of increasing control of unhealthy behaviour.

The problem with both of the hypotheses mentioned above is, however, that they should apply similarly to both men and women, but the increase of the non-married excess mortality was clearly more systematic among women. Detailed cause- and country-specific studies are needed in order to improve our understanding of the trends described in this paper.

\section{Acknowledgements}

The study was supported by funding from the Academy of Finland (projects 51640, 70631, and 48600). 
Demographic Research - Special Collection 2: Article 12

-- Determinants of Diverging Trends in Mortality --

\section{References}

Hajdu P, McKee M, Bojan F. (1995). "Changes in premature mortality differentials by marital status in Hungary and in England and Wales." European Journal of Public Health, 5:259-264.

Hu Y, Goldman N. (1990) "Mortality differentials by marital status: An international comparison." Demography, 27, 2:233-250.

Joung I. (1996) Marital status and health. Descriptive and explanatory studies. Alblasserdam: Offsetdrukkerij Haveka.

Koskinen S, Martelin T, Rissanen H. (1999) "Siviilisäätyjen kuolleisuuserot - kasvava kansanterveysongelma.” Sosiaalilääketieteellinen Aikakauslehti, 36:271-284.

Mackenbach J. P, Kunst A. E. (1997) "Measuring the magnitude of socioeconomic inequalities in health: an overview of available measures illustrated with two examples from Europe." Social Science \& Medicine, 44, 6:757-771.

Martelin T. (1996) Sociodemographic differential mortality at older ages in Finland. In: Caselli G, Lopez A, editors. Health and mortality trends among elderly populations. Oxford: Glarendon Press: 112-134.

Martikainen, P, Valkonen T. (1996) "Mortality after death of spouse in relation to duration of bereavement in Finland." Journal of Epidemiology and Community Health, 50:264-268.

Palloni A. (2001) Living arrangements of older persons. Population Bulletin of the United Nations: Living Arrangements of Older Persons. United Nations, 42/43:54-110.

Pampel F. C. (1992) Trends in living alone among the elderly in Europe. In: Rogers A, editor. Elderly Migration and Population Redistribution: A Comparative Perspective. London: Belhaven Press.

Statistics Finland. (1991). Population 1991:11, Population Structure. Helsinki.

Statistics Finland. (1992). Population 1992:7, Families. Helsinki.

Valkonen T. (1999) The widening differentials in adult mortality by socioeconomic status and their causes. In: Chamie $\mathrm{J}$ and Cliquet R L, editors. Health and Mortality. Issues of Global Concern. Leuven: Proceedings of the symposium on Health and Mortality, Brussels, 19-22 November 1997, Population Division, Department of Economic and Social Affairs, United Nations Secretariat and Population and Family Study Centre, Flemish Scientific Institute. 
Valkonen T. (2001): Trends in differential mortality in European countries. In: Vallin J, Meslé F, Valkonen T. Trends in mortality and differential mortality in Europe, Strasbourg: Council of Europe Publishing: 185-328.

Watson P. (1995) "Explaining rising mortality among men in eastern Europe." Social Science \& Medicine 41, 7:923-934. 


\section{Appendix: Sources of data}

\section{Belgium}

United Nations Demographic Yearbook 1974, 1975, 1980, 1985.

(Number of deaths and death rates, 1970 and 1981)

Statistiques Demographiques 1988-92. Institut National de Statistique.

(Populations and numbers of deaths, 1990 and 1992)

Statistiques Demographiques 1991:1, 1992:3, 1995:1. Institut National de

Statistique.

Annuaire Statistique de la Belgique. Tome 113. 1995. Institut National de

Statistique.

Statistics Belgium. Processing: Interface Demography, Vrije Universiteit

Brussel 2001.

(Populations and number of deaths 1999)

Canada

United Nations Demographic Yearbook 1973, 1975, 1985, 1996.

(Populations and death rates 1971, number of deaths and death rates 1983 and 1994)

\section{Denmark}

United Nations Demographic Yearbook 1974, 1975, 1980, 1985.

(Number of deaths and death rates, 1972 -1984)

Danmarks Statistik.

(Number of deaths and populations, 1995)

England and Wales

Census 1971, Great Britain. Age, marital condition and general tables. Office of Population Census and Surveys, London.

(Population 1971)

United Nations Demographic Yearbook 1980.

(Number of deaths and death rates 1979)

Series DH1 no. 26 (Table 3).

(Number of deaths 1991)

Census 1991, Great Britain. Sex, age and marital status. Office of Population 
Census and Surveys. General Register Office for Scotland.

(Population 1991)

Series DH1 no. 31 (Tables 9 and 10). Age, sex and marital status.

(Number of deaths and death rates 1998)

Finland

Vital Statistics 1971. Official Statistics of Finland VIA:133.

(Number of deaths and population 1971)

Population 1981. Volume 1. Structure of Population and Vital Statistics. Whole country and provinces. Official Statistics of Finland VIA:146.

(Number of deaths and population 1981)

Vital Statistics 1991. Population 1994:2.

(Number of deaths and population 1991)

Vital Statistics 1997. Population 1998:12.

(Number of deaths and population 1997)

France

La situation demographique en 1970-1996. INSEE.

(Populations and number of deaths)

Japan

United Nations Demographic Yearbook 1973, 1975, 1980, 1996.

(Population and death rates 1970, death rates 1980, number of deaths 1995).

Final Report of the 1990 Population Census. Population of Japan (statistical tables). Statistics

Bureau, management and Coordination Agency. (Population 1970 and 1980).

Population Census of Japan 1995, Volume 2-1. Statistics Bureau Management and Coordination Agency Government of Japan.

(Population 1995)

Netherlands

United Nations Demographic Yearbook 1980, 1996.

(Number of deaths and death rates, 1979 and 1995)

Statistical Yearbook of the Netherlands 1974. Netherlands Central Bureau of

Statistics. 
(Populations, December $31^{\text {st }}$ 1973)

Burgerlijke staat en doodsoorzaak. Ontwikkelingen in Nederland 1950-1990.

Statistics Netherlands, Voorburg 1995.

(Number of deaths 1971-1975 and 1986-1990; populations 1986-1990).

Norway

United Nations Demographic Yearbook 1975, 1980, 1996.

(Death rates 1970-1991; number of deaths 1979)

Folkemengden efter alder og ekteskapelig status. 31 desember 1970. Statistisk sentralbyrå, Oslo 1971.

(Populations 1970)

Befolkningsstatistikk 1991. Hefte II. Folkmengd 1. januar. Statistisk sentralbyrå, Oslo 1991.

(Populations 1991)

Population statistics, Statistics Norway.

(Populations and number of deaths 1997)

Sweden

United Nations Demographic Yearbook 1974, 1975, 1980.

(Number of deaths and death rates 1973 and 1979)

Befolkningsstatistik 1991, 1997. Del 4. Statistiska Centralbyrån, Stockholm 1992, 1998.

(Populations and number of deaths, 1991 and 1997) 
Table 1: $\quad$ Unweighted average proportion (\%) of 65-74 year old population in marital status categories by sex in 1970/71, 1980/81, 1990/91 and 1996/97 in 10 countries.

\begin{tabular}{lrrrr}
\hline Men & $\mathbf{1 9 7 0 / 7 1}$ & $\mathbf{1 9 8 0 / 8 1}$ & $\mathbf{1 9 9 0 / 9 1}$ & $\mathbf{1 9 9 6 / 9 7}$ \\
\hline Single & 8.5 & 7.8 & 7.4 & 7.4 \\
Divorced & 2.0 & 3.1 & 4.6 & 6.0 \\
Widowed & 12.4 & 10.4 & 9.1 & 8.5 \\
All non-married & 22.8 & 21.3 & 21.1 & 21.9 \\
Married & & & & \\
All & 77.2 & 78.7 & 78.9 & 78.1 \\
\hline & 100.0 & 100.0 & 100.0 & 100.0 \\
\hline Women & & & & \\
& $1970 / 71$ & $1980 / 81$ & $1990 / 91$ & $\mathbf{1 9 9 6 / 9 7}$ \\
\hline Single & 12.4 & 9.5 & 7.3 & 6.6 \\
Divorced & 2.6 & 4.0 & 5.5 & 6.9 \\
Widowed & 39.4 & 38.2 & 34.7 & 31.9 \\
All non-married & 54.5 & 51.7 & 47.5 & 45.4 \\
Married & & & & \\
\hline All & 45.5 & 48.3 & 52.5 & 100.0 \\
\hline
\end{tabular}


Table 2: $\quad$ Changes from 1980/81 to 1996/97 in the absolute excess mortality (deaths/1000) of non-married groups as compared to the married group, by sex and country

\begin{tabular}{|c|c|c|c|c|}
\hline \multicolumn{5}{|l|}{ Men } \\
\hline & Single & Divorced & Widowed & All non-married \\
\hline Belgium & -0.1 & -9.1 & 0.0 & -1.8 \\
\hline Japan & -21.5 & 10.1 & -5.0 & -1.2 \\
\hline France & 0.8 & 4.7 & -3.0 & -0.5 \\
\hline Sweden & 5.7 & -4.4 & -3.1 & 0.4 \\
\hline Engl. \& Wales & 7.4 & -15.1 & -1.8 & 1.6 \\
\hline Norway & 10.1 & -0.8 & -4.5 & 3.6 \\
\hline Finland & 9.7 & -0.1 & -0.6 & 3.7 \\
\hline Netherlands & 9.1 & -0.6 & 1.8 & 4.2 \\
\hline Canada & 11.2 & 8.2 & -1.6 & 4.8 \\
\hline Denmark & 13.0 & 1.0 & 3.5 & 6.7 \\
\hline \multicolumn{5}{|l|}{ Women } \\
\hline & Single & Divorced & Widowed & All non-married \\
\hline Japan & -18.3 & 3.9 & -2.1 & -1.3 \\
\hline Norway & -0.8 & -0.7 & -0.6 & -0.7 \\
\hline Sweden & 1.5 & 0.3 & 0.6 & 0.6 \\
\hline Finland & 2.3 & 0.3 & 0.1 & 0.6 \\
\hline France & 1.8 & 2.4 & 0.2 & 0.6 \\
\hline Engl. \& Wales & -2.0 & 1.1 & 1.7 & 1.2 \\
\hline Canada & 4.0 & 1.0 & 1.3 & 1.7 \\
\hline Belgium & 2.3 & -0.6 & 2.0 & 1.8 \\
\hline Netherlands & 4.0 & 5.3 & 1.8 & 2.7 \\
\hline Denmark & 1.8 & 7.1 & 2.9 & 3.7 \\
\hline
\end{tabular}


Demographic Research - Special Collection 2: Article 12

-- Determinants of Diverging Trends in Mortality --

Table 3: $\quad$ Changes (percent points) from 1980/81 to 1996/97 in the relative excess mortality of non-married groups compared to the married group."

\begin{tabular}{lrrrr}
\hline Men & Single & Divorced & Widowed & All non-married \\
\hline France & 17.6 & 28.8 & 5.0 & 13.2 \\
Belgium & 15.9 & -5.9 & 23.9 & 15.2 \\
Japan & -34.3 & 71.3 & -3.2 & 17.4 \\
Sweden & 41.9 & 4.7 & 6.8 & 21.2 \\
Netherlands & 34.6 & 11.1 & 16.1 & 22.6 \\
Denmark & 39.8 & 10.1 & 14.8 & 23.6 \\
Engl. \& Wales & 38.7 & -19.0 & 20.3 & 25.1 \\
Norway & 50.0 & 19.3 & -0.6 & 28.7 \\
Finland & 53.3 & 29.1 & 22.9 & 37.0 \\
Canada & 66.7 & 52.5 & 16.7 & 41.5
\end{tabular}

\begin{tabular}{lrrrr}
\hline Women & Single & Divorced & Widowed & All non-married \\
\hline Norway & 5.6 & 6.9 & 3.2 & 3.1 \\
Japan & -63.6 & 59.6 & -0.1 & 11.4 \\
France & 28.2 & 30.1 & 12.1 & 16.3 \\
Sweden & 29.9 & 15.8 & 14.4 & 16.5 \\
Engl. \& Wales & -3.8 & 13.1 & 20.4 & 16.5 \\
Denmark & 8.5 & 35.0 & 14.0 & 17.9 \\
Finland & 37.9 & 19.3 & 15.2 & 20.5 \\
Canada & 37.3 & 15.7 & 18.0 & 20.5 \\
Netherlands & 31.8 & 43.5 & 18.5 & 24.3 \\
Belgium & 30.6 & 14.7 & 36.9 & 33.8 \\
\hline
\end{tabular}

Note:

* The relative excess mortality of the non-married groups compared to the married groups was calculated as $(\mathrm{dn}-\mathrm{dm}) / \mathrm{dm} \times 100$, where $\mathrm{dn}$ and $\mathrm{dm}$ are the death rates for the non-married and married groups, respectively. The change from 1980/81 to $1996 / 97$ in the relative excess mortality was calculated as the difference between the relative excess mortality in 1996/97 and $1980 / 81$. 
Demographic Research - Special Collection 2: Article 12

-- Determinants of Diverging Trends in Mortality --

Table 4: $\quad$ Changes from 1980/81 to 1996/97 in the absolute excess mortality (deaths/1000) of non-married groups compared to the married. Unstandardized values compared to age-standardized.

\begin{tabular}{|c|c|c|c|c|}
\hline \multicolumn{5}{|l|}{ Men } \\
\hline & Single & Divorced & Widowed & All non-married \\
\hline \multicolumn{5}{|l|}{ Finland } \\
\hline Unstandardized & 9.7 & -0.1 & -0.6 & 3.7 \\
\hline Age-standardized & 5.0 & -4.2 & -2.9 & 0.5 \\
\hline \multicolumn{5}{|l|}{ France } \\
\hline Unstandardized & 0.8 & 4.7 & -3.0 & -0.5 \\
\hline Age-standardized & 0.8 & 3.2 & -3.2 & -0.9 \\
\hline \multicolumn{5}{|l|}{ Sweden } \\
\hline Unstandardized & 5.7 & -4.4 & -3.1 & 0.4 \\
\hline Age-standardized & 9.3 & -4.9 & -0.3 & 3.1 \\
\hline \multicolumn{5}{|l|}{ Women } \\
\hline & Single & Divorced & Widowed & All non-married \\
\hline \multicolumn{5}{|l|}{ Finland } \\
\hline Unstandardized & 2.3 & 0.3 & 0.1 & 0.6 \\
\hline Age-standardized & 4.2 & 1.1 & 1.0 & 1.8 \\
\hline \multicolumn{5}{|l|}{ France } \\
\hline Unstandardized & 1.8 & 2.4 & 0.2 & 0.6 \\
\hline Age-standardized & 2.0 & 2.4 & 0.7 & 1.1 \\
\hline \multicolumn{5}{|l|}{ Sweden } \\
\hline Unstandardized & 1.5 & 0.3 & 0.6 & 0.6 \\
\hline Age-standardized & 4.3 & -0.6 & 0.9 & 1.4 \\
\hline
\end{tabular}


Demographic Research - Special Collection 2: Article 12

-- Determinants of Diverging Trends in Mortality --
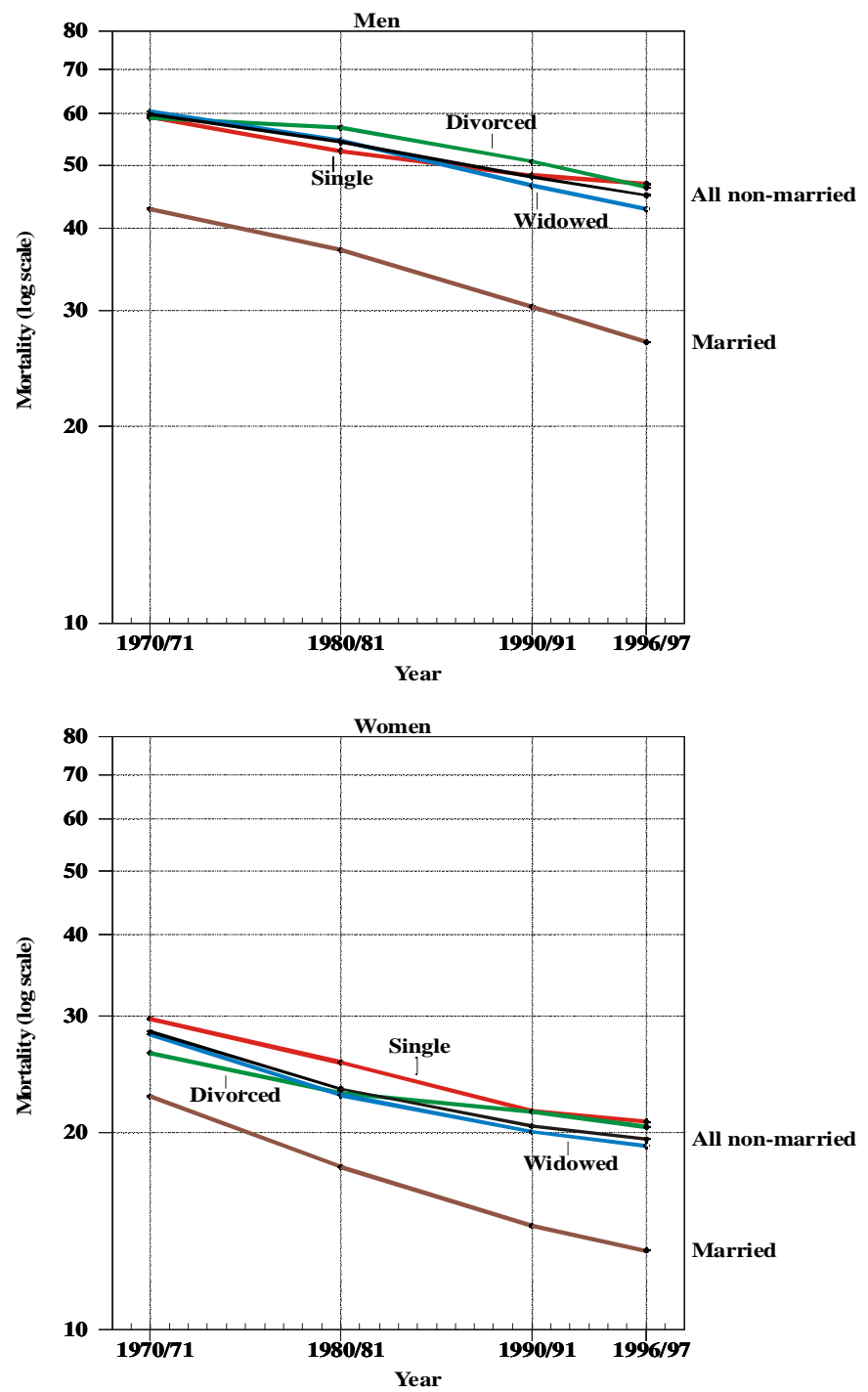

Figure 1: $\quad$ Average mortality (deaths /1000) by marital status in 1970/71-1996/97 for 10 countries, men and women aged 65-74 (logarithmic scale). 
Demographic Research - Special Collection 2: Article 12

-- Determinants of Diverging Trends in Mortality --
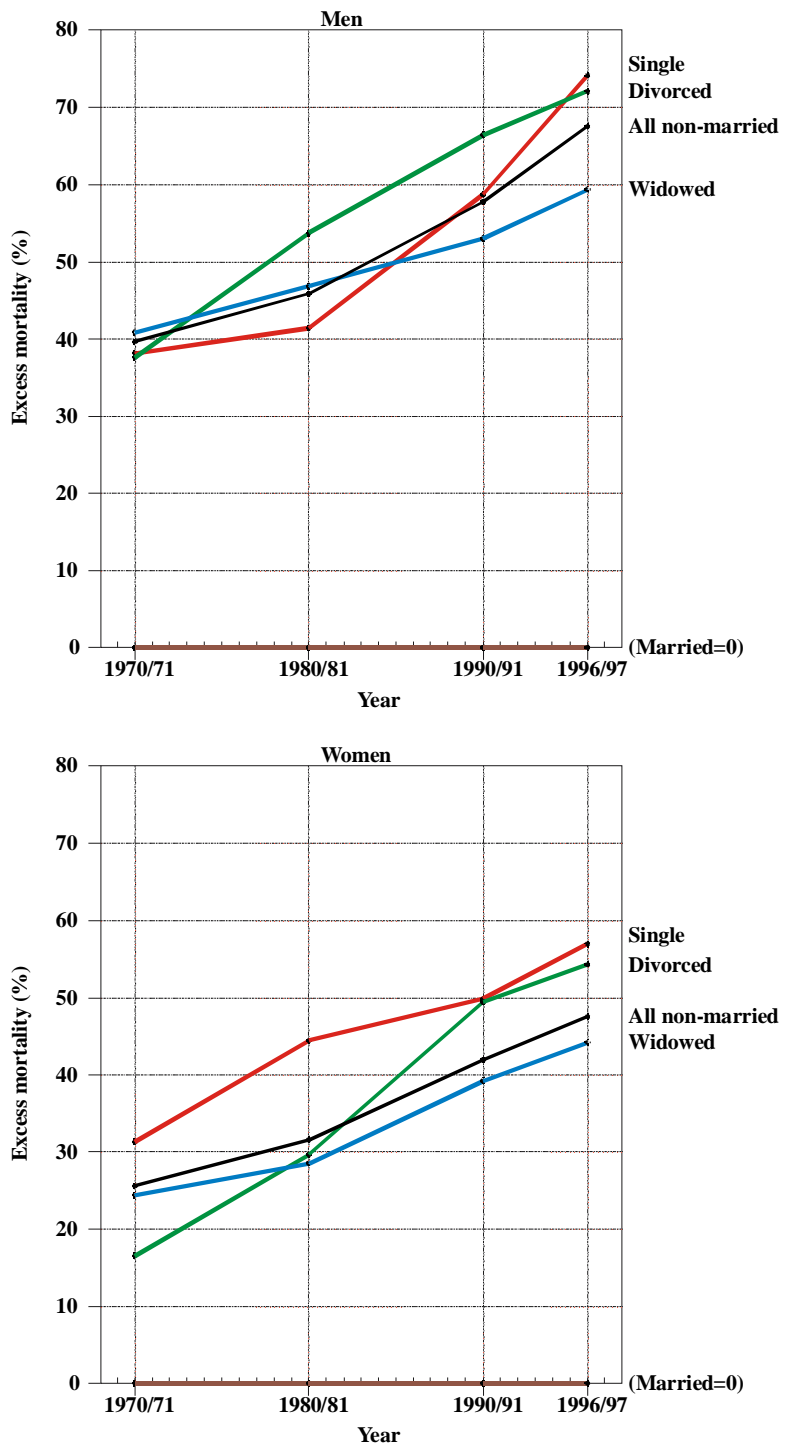

Figure 2: $\quad$ Average relative excess mortality (\%) of the non-married groups compared to the married group in 1970/71-1996/97 in 10 countries, men and women aged 65-74. 
Demographic Research - Special Collection 2: Article 12

-- Determinants of Diverging Trends in Mortality --
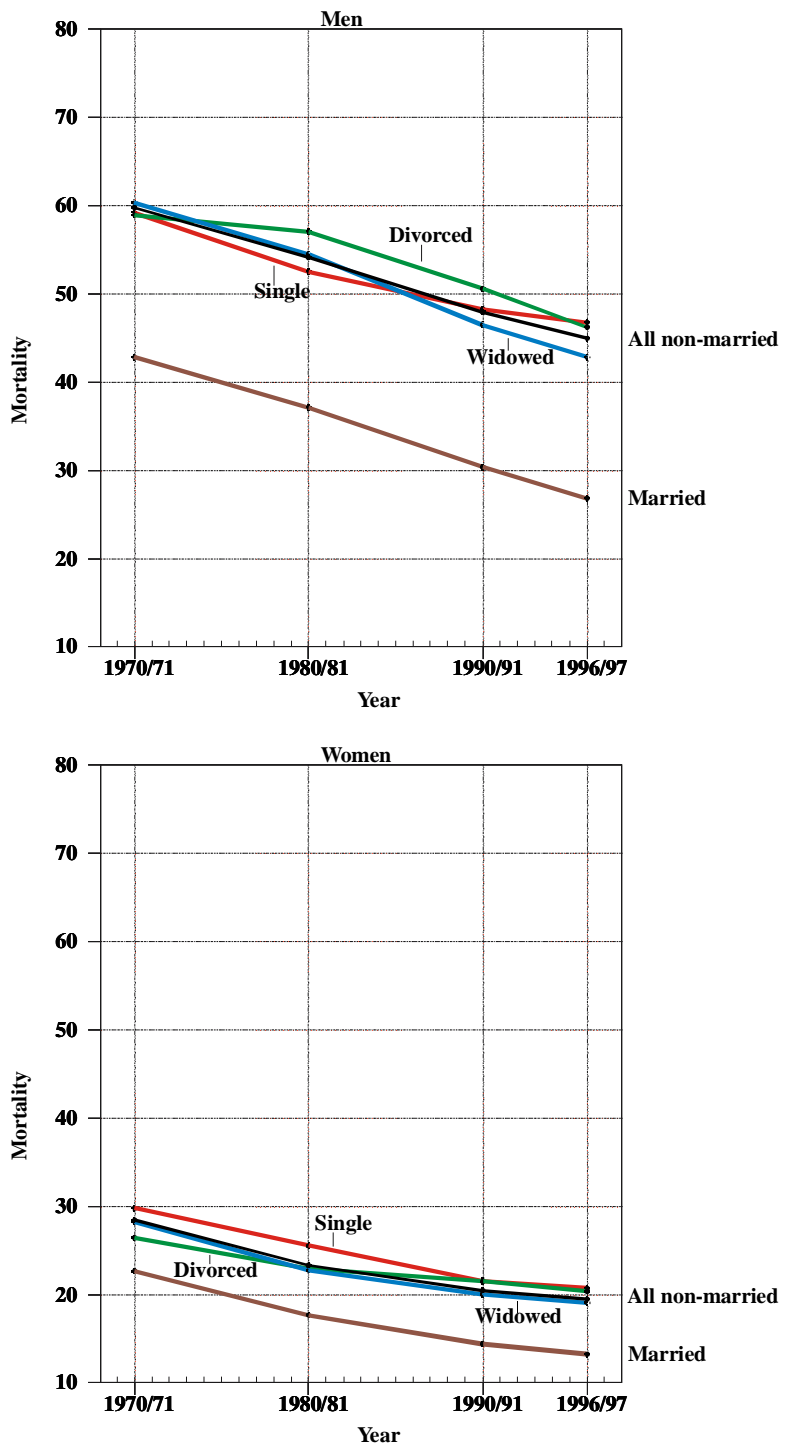

Figure 3: $\quad$ Average mortality (deaths/1000) by marital status in 1970/71-1996/97 for 10 countries, men and women aged 65-74 (linear scale) 
Demographic Research - Special Collection 2: Article 12

-- Determinants of Diverging Trends in Mortality --
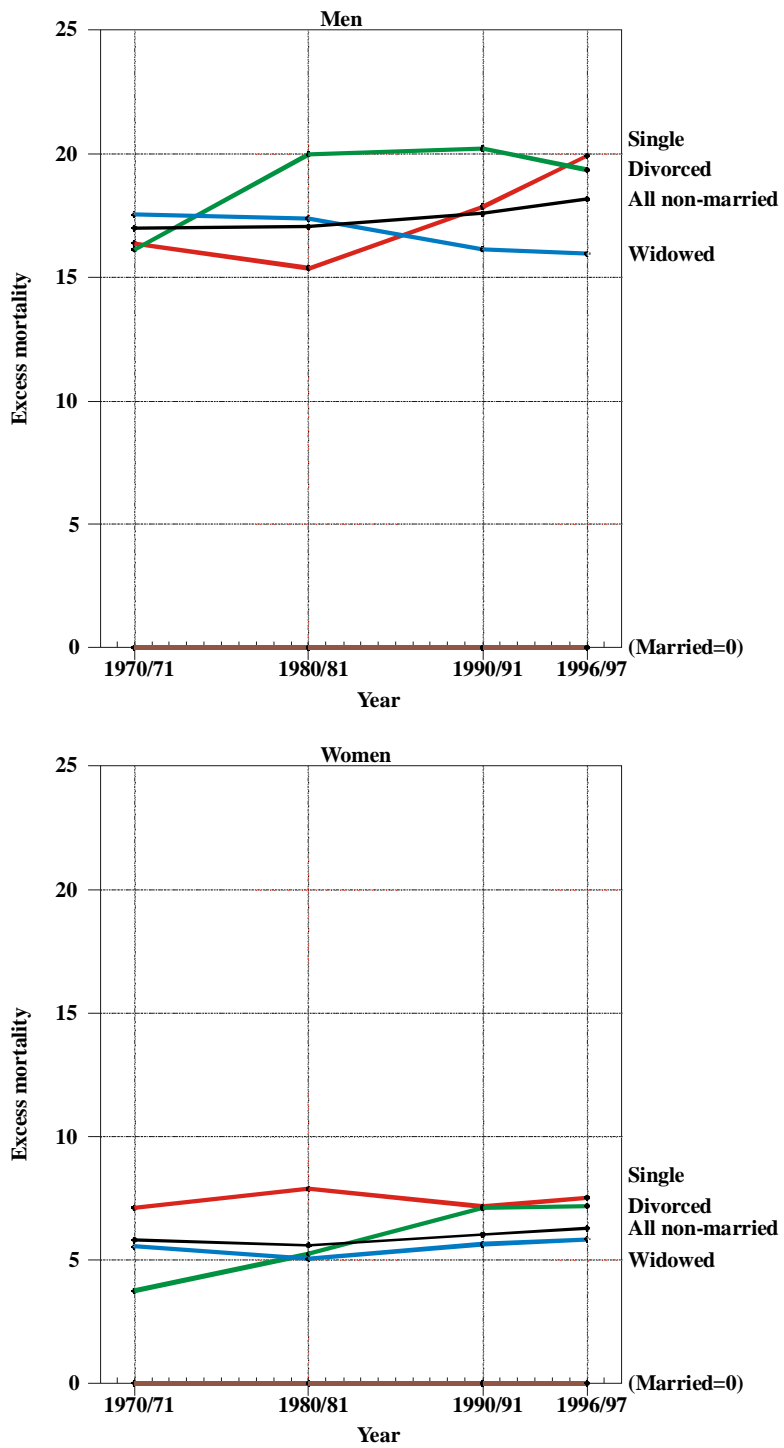

Figure 4: $\quad$ Average absolute excess mortality (deaths/1000) of the non-married groups compared to the married group in 1970/71-1996/97 in 10 countries, men and women aged 65-74. 
Demographic Research - Special Collection 2: Article 12

-- Determinants of Diverging Trends in Mortality --
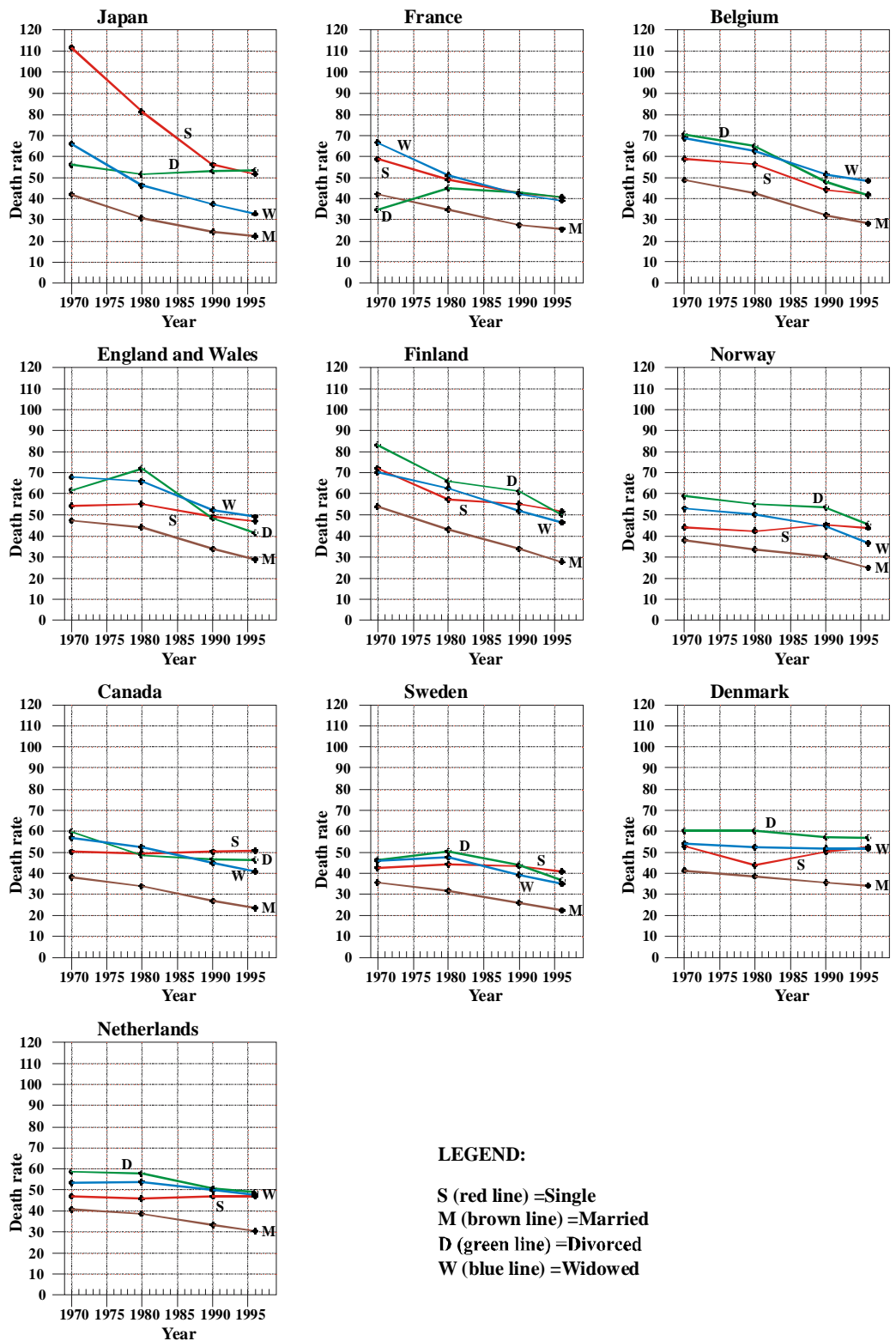

\section{LEGEND:}

$\mathrm{S}($ red line $)=$ Single

M (brown line $)=$ Married

$\mathrm{D}$ (green line $)=$ Divorced

W $($ blue line $)=$ Widowed

Figure 5: $\quad$ Trends in death rates (per 1000) for marital status from 1970/71 to 1996/97 in 10 countries, men aged 65-74. 
Demographic Research - Special Collection 2: Article 12

-- Determinants of Diverging Trends in Mortality --
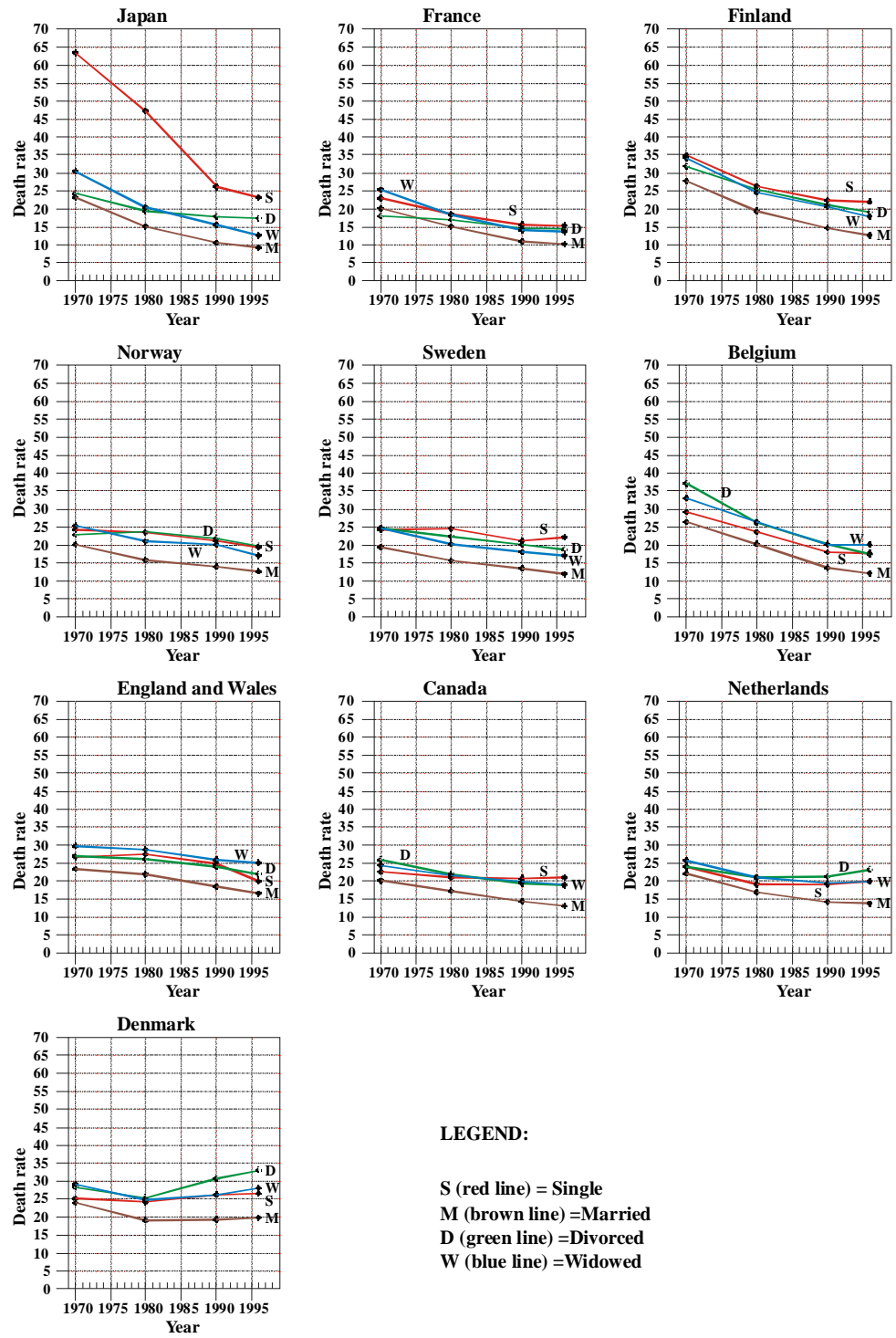

LEGEND:

$S($ red line $)=$ Single

$M($ brown line $)=$ Married

$\mathrm{D}$ (green line $)=$ Divorced

W $($ blue line $)=$ Widowed

Figure 6: $\quad$ Trends in death rates (per 1000) for marital status from 1970/71 to 1996/97 in 10 countries, women aged 65-74. 
Demographic Research - Special Collection 2: Article 12

-- Determinants of Diverging Trends in Mortality -- 